\title{
Roller Type and Operating Speed Effects on Rye Termination Rates, Soil Moisture, and Yield of Sweet Corn in a No-till System
}

\author{
Ted S. Kornecki ${ }^{1}$, Francisco J. Arriaga, and Andrew J. Price \\ USDA-ARS, National Soil Dynamics Laboratory, 411 S. Donahue Drive, \\ Auburn, AL 36832
}

Additional index words. no-till sweet corn, rye cover crop, roller/crimper, termination rate

\begin{abstract}
A field experiment was conducted in Cullman, AL, to evaluate the effects of three different rollers/crimpers on the termination of a rye (Secale cereale $\mathrm{L}$ ) winter cover crop, soil moisture, and yield of sweet corn (Zea mays saccharata L.) in a no-till system. The following roller types were tested: a straight bar roller, a smooth roller with crimper, and a two-stage roller. These rollers were tested at operating speeds of 3.2 $\mathrm{km} \cdot \mathrm{h}^{-1}$ and $6.4 \mathrm{~km} \cdot \mathrm{h}^{-1}$. The three rollers/crimpers were compared with a smooth drum roller (no crimping bars) plus glyphosate applied at rate $1.0 \mathrm{~kg} \cdot \mathrm{ha}^{-1}$ used as a control. Rye termination dates were selected to be 3 weeks before the recommended sweet corn planting date, which is in the beginning of May for this region. Data indicate that at 3 weeks after rolling for all seasons $(2006-2008), 100 \%$ rye termination was reached with the smooth drum roller and glyphosate. Two weeks after rolling, average rye termination rates by rollers/crimpers alone were $54.6 \%, 30.0 \%$, and $50.4 \%$ in 2006,2007 , and 2008 , respectively. Three weeks after rolling, rye termination rates increased only by $\approx 10 \%$ compared with 2 weeks after rolling. These termination levels were below the recommended rate of $90 \%$ termination necessary for planting a cash crop into the cover residue. Lower rye termination was probably caused by rolling the rye in an early growth stage (flowering stage). The rollers' operating speed did not influence rye termination rates. Similarly, roller type did not affect soil moisture during the first and second week after rolling. Applying glyphosate with rolling did not increase yield of sweet corn in any of the three growing seasons, and in 2006 , sweet corn yield was lower compared with the roller alone treatments. These results are important to vegetable organic systems, in which use of herbicides is not allowed. No significant difference in sweet corn yield was found between operating speeds of $3.2 \mathrm{~km} \cdot \mathrm{h}^{-1} \mathrm{vs} .6 .4 \mathrm{~km} \cdot \mathrm{h}^{-1}$ and between the assigned treatments in all growing seasons. However, significant differences in sweet corn yield were detected between the years, most likely as a result of different weather patterns. The lowest sweet corn yield of $3513 \mathrm{~kg} \cdot \mathrm{ha}^{-1}$ was reported in 2007 as a result of severe drought in spring and summer of 2007. The highest yield of $15,613 \mathrm{~kg} \cdot \mathrm{ha}^{-1}$ was recorded in 2006 . In 2008 , the yield was $10,158 \mathrm{~kg} \cdot \mathrm{ha}^{-1}$. Although the different roller designs were not as effective in ending the rye cover crop compared with the glyphosate treatment, sweet corn yields were unaffected. Multiple rolling operations over the same area could be useful if greater rye termination levels are required without the use of a herbicide, but this recommendation should be tested experimentally in more detail.
\end{abstract}

Cover crops are an integral element in notill conservation systems because they provide important benefits to soils and plants. Covers must produce large amounts of biomass to maximize these benefits (Brady and Weil, 1999). A commonly used cover crop in the southern United States is rye (Secale cereale L.), which can produce 3,000 to

Received for publication 23 Sept. 2011. Accepted for publication 29 Nov. 2011

We acknowledge Mr. Arnold Caylor, superintendent at the Horticultural Research Station, Cullman, $\mathrm{AL}$, for his technical assistance.

The use of trade names or company names does not imply endorsement by USDA-Agricultural Research Service.

${ }^{1}$ To whom reprint requests should be addressed; e-mail ted.kornecki@ars.usda.gov.
$10,000 \mathrm{~kg} \cdot \mathrm{ha}^{-1}$ per year (Bowen et al., 2000). Primary benefits of using rye as a cover crop include protection of soil from the impact of rainfall energy leading to reduced soil erosion and surface runoff, decreased soil compaction, and increased infiltration (Kern and Johnson, 1993; McGregor and Mutchler, 1992; Raper et al., 2000a, 2000b; Reeves, 1994). Cover crops also provide a physical barrier on the soil surface, which inhibits weed emergence and growth. In addition to providing a physical barrier, rye has allelopathic properties that provide weed control similar to applying a pre-emergence herbicide (Barnes and Putman, 1986; Hoffman et al., 1996). Additional benefits are associated with improving soil physical/chemical properties as a result of increased soil organic carbon content, resulting in better crop growth.
Rolling/crimping technology has been used to manage mature cover crops by flattening and crimping cover crops such as rye in notill conservation systems. Crimping cover crop tissue causes plant injury and accelerates its termination or senescence. In no-till conservation systems of the southern United States, termination of cover crops should be performed 3 weeks before planting the cash crop, which is similar to standard burndown recommendations by most agricultural extension services. Results from previous research have shown that when rye rolling was performed at the optimal growth stage of early milk to soft dough, the termination rate for rye was typically above $90 \% 3$ weeks after rolling (Ashford and Reeves, 2003; Kornecki et al., 2006). Nelson et al. (1995) also stated that a later growth stage for rye such as a soft dough might be ideal for mechanical termination. Most agricultural extension services recommend ending the cover crop at least 2 weeks before planting the cash crop to prevent the cover crop from competing for soil moisture. According to Hargrove and Frye (1987), a minimum time for rolling/crimping should be at least $14 \mathrm{~d}$ before planting of the cash crop to enable soil water recharge before planting.

Optimum residue conditions for planting a cash crop are usually reached 3 weeks after termination, at which time the residue is dry, crisp, brittle, and easy to penetrate with equipment.

In vegetable production, however, planting must be completed within the recommended dates for a specific climatic region to avoid yield reduction of the vegetable crop. This time restriction may not allow the cover crop to reach the recommended growth stage for termination. To speed up the cover crop termination process, herbicide application has been implemented along with rolling in conservation systems of the Southeast for field and vegetable crops. However, herbicide use is not allowed in organic vegetable production; thus, cover crop management must be done mechanically by cutting/incorporating or through rolling/crimping technology. Different roller designs have been developed to roll and crimp cover crops; however, none have been evaluated in no-till vegetable production systems for which the recommended time for cover crop termination might need to be adjusted to follow the recommended planting date of the cash crop.

The objective of this study was to determine the impact of different roller designs and two different rolling speeds on mechanical termination of a cereal rye cover crop and their effects on soil volumetric moisture content and yield of a no-till sweet corn system.

\section{Materials and Methods}

The experiment was conducted at the North Alabama Horticultural Research Center in Cullman, AL, on a Hartsells fine sandy loam soil (fine-loamy, siliceous, subactive, thermic Typic Hapludults). Rye as a winter cover crop was planted on 4 Oct. 2005, 6 Oct. 
2006, and 10 Oct. 2007 at a rate of 101 $\mathrm{kg} \cdot \mathrm{ha}^{-1}$ using a Tye ${ }^{\mathrm{TM}}$ no-till drill (AGCO, Duluth, GA). Rolling treatments to end rye were applied 14 Apr., 12 Apr., and 23 Apr. in 2006, 2007, and 2008, respectively, when rye was at or just after the flowering growth stage. The rye termination date was based on a recommended planting date for sweet corn, which is planted relatively early in the spring to produce an optimum yield. The recommended planting time for sweet corn in northern Alabama is early May.

Before treatment application, the height and biomass of rye were measured. The height was measured at 10 randomly chosen locations per each of 28 plots $(15 \mathrm{~m} \times 5.5 \mathrm{~m})$ and averaged for each plot. Biomass was collected from two different locations in each plot using a $0.25-\mathrm{m}^{2}$ area $(0.5 \mathrm{~m} \times 0.5 \mathrm{~m}$ square $)$ steel wire frame. The collected rye biomass was oven-dried for $72 \mathrm{~h}$ at $55^{\circ} \mathrm{C}$ using an electric oven (Model No. SC-350; Grieve Corporation, Round Lake, IL). To minimize the interference between the cover crop and the cash crop planting operation, rolling direction was parallel to both rye rows and sweet corn planting direction. Sweet corn (var. Silver Queen) was planted directly into the rye residue cover on 8 May 2006, 7 May 2007, and 14 May 2008 using a Monosem no-till planter (Monosem Corporation, Edwardsville, KS) using 102-cm row spacing. Sweet corn was hand harvested on 14 Aug. 2006, 23 Aug. 2007, and 8 Aug. 2008. Supplemental application of $83 \mathrm{~kg} \cdot \mathrm{ha}^{-1} \mathrm{~N}$ ammonium nitrate $\left(\mathrm{NH}_{4} \mathrm{NO}_{3}\right)$ was broadcast before planting each year. Another $83 \mathrm{~kg} \cdot \mathrm{ha}^{-1} \mathrm{~N}$ was applied at lay by $\approx 3$ weeks after the corn was planted. Each year, to control weeds, two herbicides, Attrex 4L (2.3 L.ha $\left.{ }^{-1}\right)$ and Dual II (1.8 $\left.\mathrm{L} \cdot \mathrm{ha}^{-1}\right)$, were applied immediately after corn planting.

Treatment arrangement is shown in Figure 1. A randomized complete block design was used with four replications (blocks). Each plot was $15 \mathrm{~m}$ long and $5.5 \mathrm{~m}$ wide to accommodate the three rollers' widths.

Three different roller designs, each having a width of $1.8 \mathrm{~m}$, were compared: 1) straight-bar roller, a design based on the original technology from Brazil (Fig. 2); 2) smooth roller with crimping bar developed at the National Soil Dynamics Laboratory (NSDL) (Fig. 3); and 3) two-stage roller also developed at the NSDL (Fig. 4). Two operating speeds were chosen: 3.2 and $6.4 \mathrm{~km} \cdot \mathrm{h}^{-1}$. The roller designs mentioned were compared with a smooth drum roller with no-crimper attached operated at $6.4 \mathrm{~km} \cdot \mathrm{h}^{-1}$ (Fig. 5) plus glyphosate applied at $1.0 \mathrm{~kg} \cdot \mathrm{ha}^{-1}$ (a.i.) as a control, which is a common practice in Alabama.

Rye termination rate was estimated based on visual observation on a scale of $0 \%$ (no injury symptoms) to $100 \%$ (complete death of all plants) (Frans et al., 1986) and was evaluated at 1,2, and 3 weeks after rolling treatment application. Volumetric soil moisture content (VMC) was measured at the time of rolling treatment and at 1,2 , and 3 weeks after treatment using a portable TDR300 meter

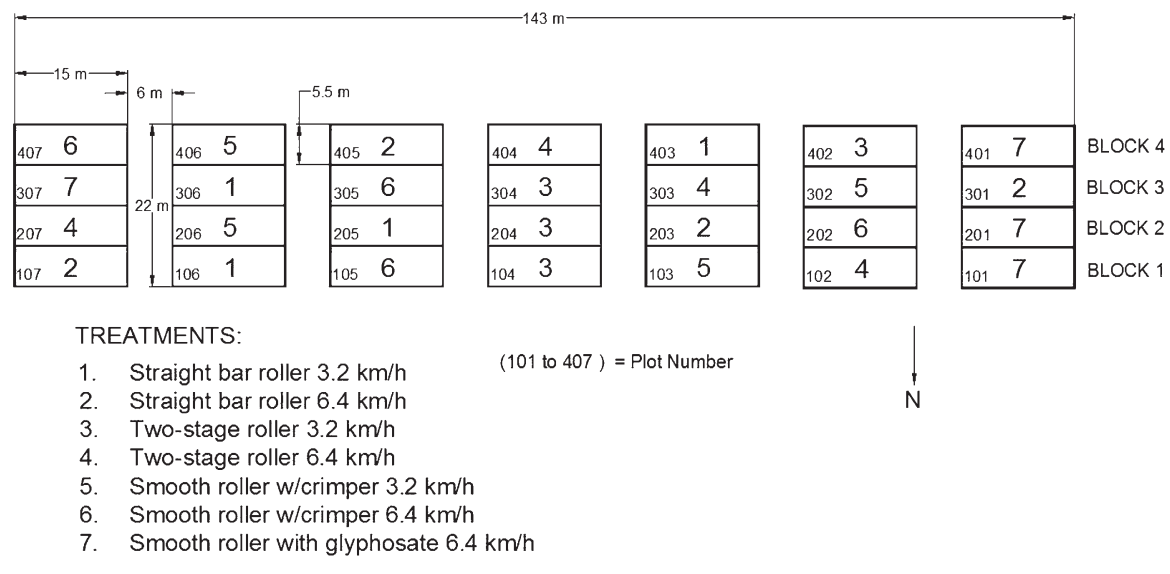

Fig. 1. Experimental field layout for a randomized complete block design (RCBD) of different roller types and operating speeds with seven treatments and four blocks (replications).

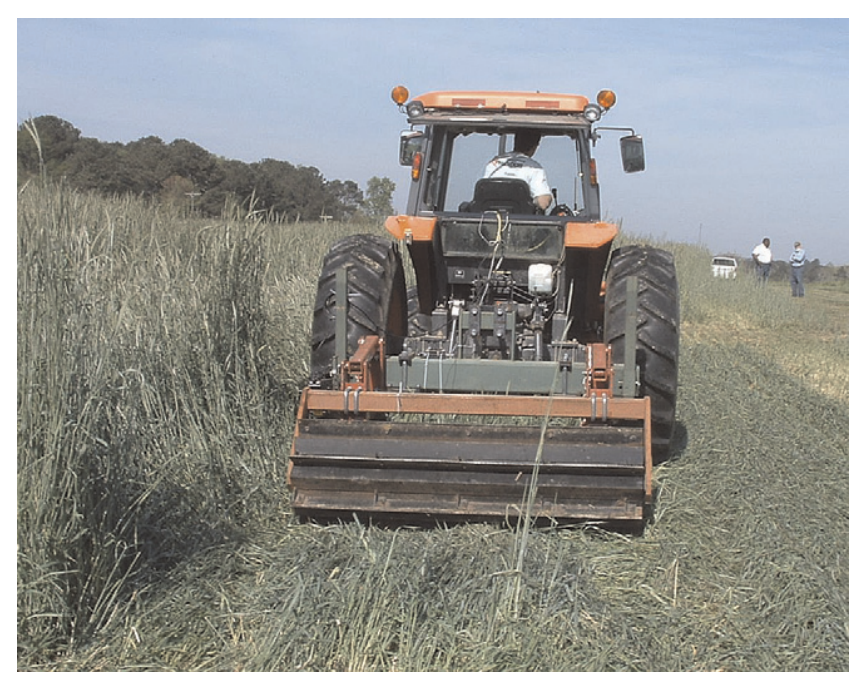

Fig. 2. Original straight-bar roller design.

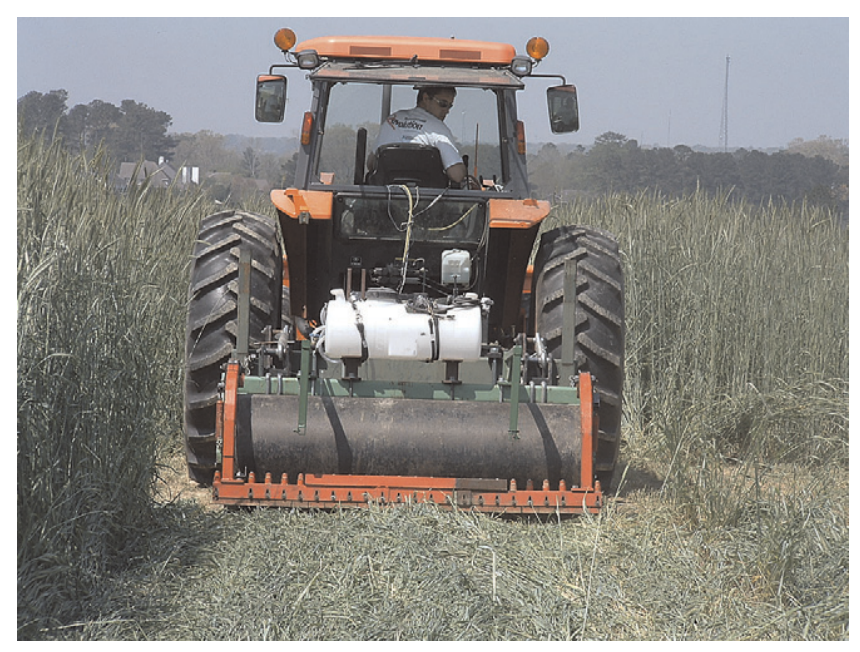

Fig. 3. Smooth roller with crimper. Design developed at the NSDL (U.S. Patent 7,604,067 B1; Kornecki and Raper, 2009).

with 12-cm long stainless steel rods (Spectrum Technologies, Plainfield, IL). Rye plant biomass and heights were collected the day before applying rolling/crimping treatments, on 13 Apr., 11 Apr., and 22 Apr. in 2006, 2007, and 2008, respectively.

Data were analyzed using an analysis of variance (ANOVA), general linear model 


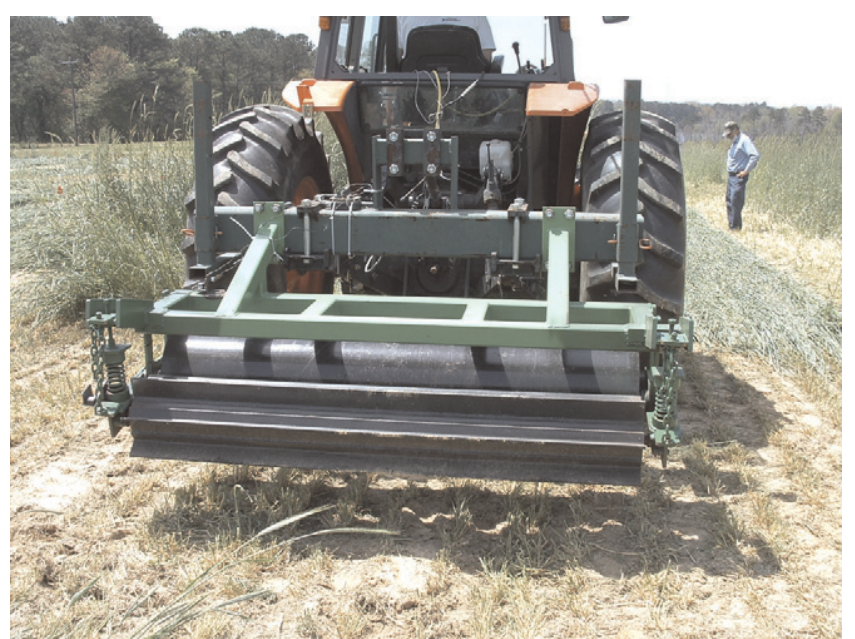

Fig. 4. Two-stage roller comprised of a smooth drum and spring loaded crimping bar drum. Design developed at the National Soil Dynamics Laboratory (U.S. Patent 7,987,917 B1; Kornecki, 2011)

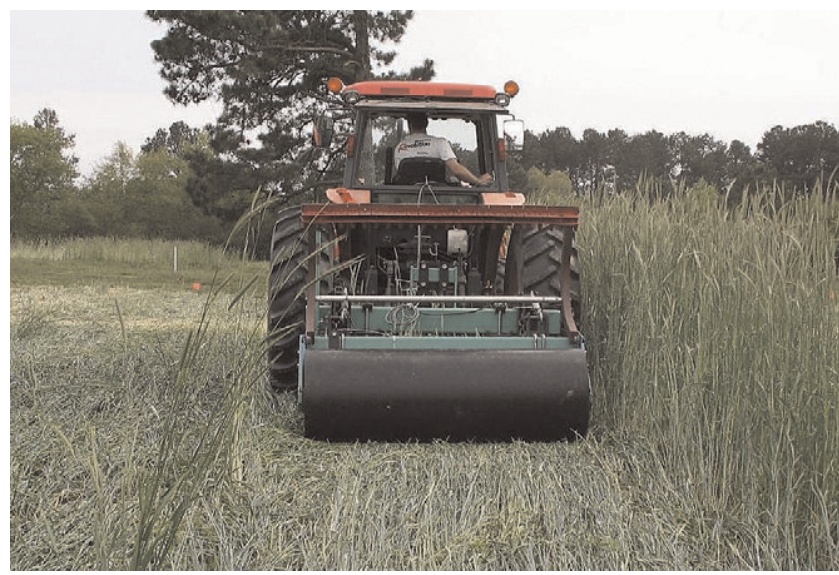

Fig. 5. Smooth roller drum without crimping bars attached.

(GLM) procedure in SAS 9.2 (SAS, 2009). To separate treatment effects, the Fisher's protected least significant difference (LSD) procedure was used at the $10 \%$ probability level $(\alpha=0.10)$. Percentages of rye termination and volumetric moisture content were transformed using an arcsine square-root (inverse sine) transformation method for analyzing binominal data expressed as percentage for wide range of values (Steel and Torrie, 1980), but this transformation did not result in a change in the ANOVA. Thus, nontransformed means are presented. When interactions between treatments by weeks and by years occurred, data were analyzed separately and when no interactions were present, data were combined using SAS (2009) ANOVA Analyst's linear model (GLM). Treatments were considered fixed effects and year was considered a random effect (Gomez and Gomez, 1984). Also, to determine differences in yield between two specific treatment means, a preplanned single degree of freedom contrast procedure as described in Steel and Torrie (1980) was performed to detect these differences at the $10 \%(\alpha=0.10)$ probability level (Table 1).

\section{Results}

Rye biomass and height. There was a significant difference in rye biomass production between years $(P=0.0002)$. Significantly higher rye biomass of $14,481 \mathrm{~kg} \cdot \mathrm{ha}^{-1}$ was obtained in 2008 compared with 2007 and 2006. In 2006, the dry rye biomass was 8581 $\mathrm{kg} \cdot \mathrm{ha}^{-1}$ and was not significantly different from the $9242 \mathrm{~kg} \cdot \mathrm{ha}^{-1}\left(\mathrm{LSD}=1424 \mathrm{~kg} \cdot \mathrm{ha}^{-1}\right)$ produced in 2007. Similarly, rye height reflected on biomass production, because the taller rye generated greater biomass. There were significant differences in rye height between the blocks in each year $(P=0.0077$, 0.0350 , and 0.0073 for 2006,2007 , and 2008 , respectively) justifying blocking of treatments. The height of rye was significantly higher $(P=0.0688)$ in $2008(180 \mathrm{~cm}$, $\mathrm{LSD}=2.4 \mathrm{~cm})$ compared with 2006 and 2007 when no differences in height were reported (171 cm in both years)

Rye termination. Because significant interactions were detected between years and treatments $(P=0.0091)$, rye termination data were analyzed separately each year. In addition, there were significant interactions between weeks and treatments; thus, data were analyzed weekly. Termination rates for rye obtained during three growing seasons are presented in Table 2. In 2006, 1, 2, and 3 weeks after rolling, there was a significant difference between the weeks' $(P<0.0001)$ termination rates. Averaged over treatments, 2006 termination rates were $39.9 \%, 61.1 \%$ and $71.2 \%(\mathrm{LSD}=1.3 \%)$ for 1,2 , and 3 weeks, respectively. In 2006, the highest termination 3 weeks after rolling for a mechanical treatment alone was observed with the two-stage roller crimper at $6.4 \mathrm{~km} \cdot \mathrm{h}^{-1}$ $(68.8 \%)$. However, this termination rate was not significantly different from those from the straight bar roller at 3.2 and $6.4 \mathrm{~km} \cdot \mathrm{h}^{-1}$ or the smooth roller with crimper at $6.4 \mathrm{~km} \cdot \mathrm{h}^{-1}$. Termination rates were similar at both speeds for the straight bar and smooth roller with crimper, whereas the two-stage roller at 3.2 $\mathrm{km} \cdot \mathrm{h}^{-1}$ had significantly lower termination rates $(63.8 \%)$ than when it was operated at $6.4 \mathrm{~km} \cdot \mathrm{h}^{-1}(68.8 \%)$. The termination rate was $100 \%$ for the smooth drum roller with glyphosate. Lower rye termination by rollers/ crimpers alone was likely associated with a rolling/crimping operation that was performed at too early a rye growth stage. Again, termination dates were selected in relation to the recommended optimum corn planting date, not on rye maturity, as a result of crop yield reduction concerns resulting from delayed cash crop planting.

In the 2007 growing season, significant differences in rye termination averaged over treatments were detected between Weeks 1 and $2(P=0.0001)$. Rye termination obtained 1 and 2 weeks after rolling were $29.8 \%$ and $39.9 \%$, respectively ( $\operatorname{LSD}=0.8 \%$ ). No data were available for Week 3 after rolling as a result of technical issues. These results agreed with the findings by Ashford and Reeves (2003) who evaluated the effects of rye growth stage on termination dates, concluding that when rye was ended in a pre-soft dough growth stage, mechanical termination was less effective. Ashford and Reeves reported rolling rye at the anthesis growth stage produced less than $80 \%$ termination rate 3 weeks after rolling, which is $10 \%$ to $15 \%$ lower than the recommended termination rate to plant a cash crop into desiccated residue cover (Reeves, 1994). In addition, Price et al. (2009) reported less than $40 \%$ termination in less mature cereal cover crops 3 weeks after termination. In 2008, rye termination averaged over the treatments was significantly different among Weeks 1,2 , and 3 $(P<0.0001)$ with rates of $38.7 \%, 57.4 \%$, and $65.6 \%(\mathrm{LSD}=1.3 \%)$, respectively. Three weeks after rolling, there were no significant differences in rye termination between roller types and speeds (58\% to $61.3 \%$ ). The only significantly higher termination rate of $99 \%$ 3 weeks after rolling was generated by the smooth roller with glyphosate application when compared with all other roller types and speeds treatments $(\mathrm{LSD}=3.4)$. Overall, the level of rye cover crop termination by rollers alone during the 3 years of the study was not sufficient to plant sweet corn 3 weeks after rolling. As stated previously, Ashford and Reeves (2003) 
indicated that an acceptable termination rate for rye must be above $90 \%$ for planting a cash crop into the rolled/crimped rye residue cover. The lower termination rate of rye in this study was most likely associated with early termination in the flowering growth stage, which likely allowed the rye to recover. Also, uneven soil surface (i.e., depressions from previous raised beds) and possibly lower soil strength resulting from higher volumetric soil moisture content that averaged $\approx 15 \%$ at rolling time could reduce crimping effectiveness. To avoid late planting of sweet corn if after the recom- mended $90 \%$ termination rate for rye, an alternative treatment may be needed to fully end rye in addition to mechanical termination using rollers. As an example, to speed up rye desiccation, a multiple rolling/crimping operation on the same area should be considered, especially for organic production systems.

Soil moisture. Volumetric soil moisture content (VMC) was measured on the day of roller treatment and after the first and second week and is shown in Table 3. In all growing seasons at the time of rolling treatment ap- plication (Week 0), there were no significant differences in VMC between treatments with mean VMC values of $14.9 \%$ in $2006,15.1 \%$ in 2007 , and $15.1 \%$ in 2008 . There were differences between the blocks $(P=0.0327)$, which might have been associated with variations in water-holding capacity resulting from different soil physical properties within the plot area.

Only during the 2007 growing season were significant differences in VMC (ranging from $13.6 \%$ to $17.6 \%$ ) observed between blocks $(P=0.0009)$, thus justifying blocking

Table 1. Preplanned single degree of freedom contrast comparisons for rolling treatments during 2006-2008.

\begin{tabular}{l} 
Contrast \\
\hline $3.2 \mathrm{~km} \cdot \mathrm{h}^{-1} \mathrm{vs}, 6.4 \mathrm{~km} \cdot \mathrm{h}^{-1}$ \\
Straight bar roller vs. two-stage \\
roller/crimper \\
Straight bar roller vs. smooth \\
roller/crimper \\
Two-stage roller with crimper vs. \\
smooth roller/crimper \\
Straight bar roller at $3.2 \mathrm{~km} \cdot \mathrm{h}^{-1} \mathrm{vs}$. \\
smooth drum with glyphosate \\
Straight bar roller at $6.4 \mathrm{~km} \cdot \mathrm{h}^{-1} \mathrm{vs}$. \\
smooth drum with glyphosate \\
Two-stage roller at $3.2 \mathrm{~km} \cdot \mathrm{h}^{-1} \mathrm{vs}$. \\
smooth drum with glyphosate \\
Two stage roller at $6.4 \mathrm{~km} \cdot \mathrm{h}^{-1} \mathrm{vs}$. \\
smooth drum with glyphosate \\
Smooth roller with crimper at \\
$3.2 \mathrm{~km} \cdot \mathrm{h}^{-1}$ vs. smooth drum \\
with glyphosate \\
Smooth roller with crimper at \\
$6.4 \mathrm{~km} \cdot \mathrm{h}^{-1}$ vs. smooth drum \\
with glyphosate \\
\hline
\end{tabular}

Treatment comparisons

Straight bar roller, smooth roller crimper, two-stage roller crimper at $3.2 \mathrm{~km} \cdot \mathrm{h}^{-1} \mathrm{vs}$. straight bar roller, smooth roller crimper, two-stage roller crimper at $6.4 \mathrm{~km} \cdot \mathrm{h}^{-1}$

Straight bar roller at $3.2 \mathrm{~km} \cdot \mathrm{h}^{-1}$, straight bar roller at $6.4 \mathrm{~km} \cdot \mathrm{h}^{-1} \mathrm{vs}$. smooth roller/crimper at $3.2 \mathrm{~km} \cdot \mathrm{h}^{-1}$, smooth roller/crimper at $6.4 \mathrm{~km} \cdot \mathrm{h}^{-1}$

Straight bar roller at $3.2 \mathrm{~km} \cdot \mathrm{h}^{-1}$, straight bar roller at $6.4 \mathrm{~km} \cdot \mathrm{h}^{-1} \mathrm{vs}$. smooth roller/crimper at $3.2 \mathrm{~km} \cdot \mathrm{h}^{-1}$, smooth roller/crimper at $6.4 \mathrm{~km} / \mathrm{h}$

Two stage roller crimper at $3.2 \mathrm{~km} \cdot \mathrm{h}^{-1}$, two-stage roller crimper at $6.4 \mathrm{~km} \cdot \mathrm{h}^{-1} \mathrm{vs}$. Smooth roller/crimper at $3.2 \mathrm{~km} \cdot \mathrm{h}^{-1}$, smooth roller/crimper at $6.4 \mathrm{~km} \cdot \mathrm{h}^{-1}$

Straight bar roller at $3.2 \mathrm{~km} \cdot \mathrm{h}^{-1} \mathrm{vs}$. rolling with a smooth drum (no crimping) with glyphosate

Straight bar roller at $6.4 \mathrm{~km} \cdot \mathrm{h}^{-1}$ vs. rolling with a smooth drum (no crimping) with glyphosate

Two-stage roller at $3.2 \mathrm{~km} \cdot \mathrm{h}^{-1}$, two-stage roller at $6.4 \mathrm{~km} \cdot \mathrm{h}^{-1} \mathrm{vs}$. rolling with a smooth drum (no crimping) with glyphosate

Two-stage roller at $6.4 \mathrm{~km} \cdot \mathrm{h}^{-1}$ vs. rolling with a smooth drum (no crimping) with glyphosate

Smooth roller/crimper at $3.2 \mathrm{~km} \cdot \mathrm{h}^{-1}$ vs. rolling with a smooth drum (no crimping) with glyphosate

Smooth roller/crimper at $6.4 \mathrm{~km} \cdot \mathrm{h}^{-1}$ vs. rolling with a smooth drum (no crimping) with glyphosate with glyphosate

Table 2. Rye termination rates (\%) for different roller types and operating speeds.

\begin{tabular}{|c|c|c|c|c|c|c|c|c|c|c|}
\hline \multirow[b]{3}{*}{ Roller type } & \multirow{3}{*}{$\begin{array}{c}\text { Speed } \\
\left(\mathrm{km} \cdot \mathrm{h}^{-1}\right)\end{array}$} & \multicolumn{3}{|c|}{1 week } & \multicolumn{3}{|c|}{2 weeks } & \multicolumn{3}{|c|}{3 weeks } \\
\hline & & 2006 & 2007 & 2008 & 2006 & 2007 & 2008 & 2006 & 2007 & 2008 \\
\hline & & \multicolumn{9}{|c|}{ Termination rate $(\%)$} \\
\hline Straight bar & 3.2 & $30 b^{2}$ & $21.3 \mathrm{~b}$ & $30 \mathrm{~b}$ & $57.5 \mathrm{~b}$ & $30 \mathrm{~b}$ & $50 \mathrm{bc}$ & $67.5 \mathrm{bc}$ & \multirow{6}{*}{$\begin{array}{l}\text { Data not } \\
\text { available }\end{array}$} & $60.5 \mathrm{~b}$ \\
\hline Smooth roller & 3.2 & $32.5 \mathrm{~b}$ & $23.8 \mathrm{~b}$ & $24.5 \mathrm{c}$ & $53.8 \mathrm{bc}$ & $30 \mathrm{~b}$ & $48.8 \mathrm{bc}$ & $63.8 \mathrm{c}$ & & $58 \mathrm{~b}$ \\
\hline with crimping bar & 6.4 & $32.5 \mathrm{~b}$ & $22.5 \mathrm{~b}$ & $31 \mathrm{~b}$ & $57.5 \mathrm{~b}$ & $31.3 \mathrm{~b}$ & $51 \mathrm{bc}$ & $67.5 \mathrm{bc}$ & & $61.3 \mathrm{~b}$ \\
\hline \multirow[t]{2}{*}{ Two-stage roller } & 3.2 & $26.3 \mathrm{c}$ & $20 \mathrm{~b}$ & $29.5 \mathrm{~b}$ & $52.5 \mathrm{c}$ & $30 \mathrm{~b}$ & $52.5 \mathrm{~b}$ & $63.8 \mathrm{c}$ & & $60 \mathrm{~b}$ \\
\hline & 6.4 & $30 \mathrm{bc}$ & $18.8 \mathrm{~b}$ & $28.3 \mathrm{bc}$ & $53.8 \mathrm{bc}$ & $28.8 \mathrm{~b}$ & $49.8 \mathrm{bc}$ & $68.8 \mathrm{~b}$ & & $60 \mathrm{~b}$ \\
\hline \multicolumn{2}{|l|}{ Least significa } & 4.2 & 5.0 & 4.8 & 3.8 & 3.6 & 3.3 & 4.6 & & 3.4 \\
\hline
\end{tabular}

${ }^{\mathrm{z}}$ Same letters indicate no significant differences within each column.

Table 3. Volumetric soil moisture content (\%) measured for different operating speeds and roller types.

\begin{tabular}{|c|c|c|c|c|c|c|c|c|c|c|c|c|c|}
\hline \multirow[b]{3}{*}{ Roller Type } & \multirow[b]{3}{*}{ Speed $\left(\mathrm{km} \cdot \mathrm{h}^{-1}\right)$} & \multicolumn{3}{|c|}{ At rolling } & \multicolumn{3}{|c|}{1 week after rolling } & \multicolumn{3}{|c|}{2 weeks after rolling } & \multicolumn{3}{|c|}{3 weeks after rolling } \\
\hline & & $\overline{2006}$ & 2007 & 2008 & 2006 & 2007 & 2008 & $\overline{2006}$ & 2007 & 2008 & $\overline{2006}$ & 2007 & 2008 \\
\hline & & \multicolumn{12}{|c|}{ Percent $(\%)$} \\
\hline Straight bar & 3.2 & 15.3 & 15.5 & 14.8 & 19.6 & 21.1 & 20.2 & 33.1 & $14.0 \mathrm{~b}^{\mathrm{x}}$ & 18.7 & 23.8 & $16.0 \mathrm{~b}$ & 21.9 \\
\hline \multirow{2}{*}{ Smooth roller with crimping bar } & 3.2 & 15.8 & 15.5 & 14.9 & 19.2 & 21.9 & 22.0 & 30.9 & $14.0 \mathrm{~b}$ & 19.1 & 23.2 & $15.6 \mathrm{bc}$ & 21.5 \\
\hline & 6.4 & 14.0 & 14.9 & 15.2 & 16.1 & 21.1 & 23.8 & 28.5 & $13.6 \mathrm{~b}$ & 19.0 & 20.7 & $15.9 \mathrm{~b}$ & 22.5 \\
\hline \multirow[t]{2}{*}{ Two-stage roller } & 3.2 & 17.0 & 14.3 & 15.6 & 19.3 & 19.9 & 22.2 & 29.6 & $12.6 \mathrm{~b}$ & 20.4 & 23.2 & $14.1 \mathrm{c}$ & 23.4 \\
\hline & 6.4 & 14.8 & 15.2 & 15.8 & 18.2 & 20.8 & 22.1 & 30.4 & $13.0 \mathrm{~b}$ & 20.1 & 22.3 & $14.3 \mathrm{bc}$ & 23.4 \\
\hline \multicolumn{2}{|c|}{$\begin{array}{l}\text { Least significant difference at } \alpha=0.1 \\
\qquad P \text {-value }\end{array}$} & 0.461 & 0.934 & 0.975 & 0.464 & 0.402 & 0.409 & 0.678 & 0.0401 & 0.322 & 0.775 & 0.0107 & 0.276 \\
\hline
\end{tabular}

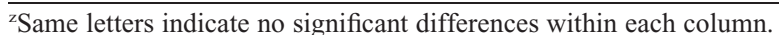

$\mathrm{NS}=$ non-significant 
in the experimental design. No significant differences in VMC between blocks were observed for the 2006 and 2008 growing seasons. One week after rolling, there were significant differences in $\mathrm{VMC}$ between years $(P<0.0001, \mathrm{LSD}=0.8 \%)$ at $18.3 \%, 20.8 \%$, and $22.2 \%$ for 2006,2007 , and 2008 , respectively. Likewise, 2 weeks after rolling, significant differences were detected in VMC among the years $(P<0.0001, \mathrm{LSD}=1.2 \%)$ at $30.9 \%$ in $2006,13.7 \%$ in 2007 , and $19.8 \%$ in 2008 . The high VMC 2 weeks after rolling in 2006 was caused by two separate rainfall events between Week 1 and Week 2 after rolling, which occurred $1 \mathrm{~d}$ before VMC was measured (Fig. 6).

Three weeks after rolling, no differences in VMC occurred between 2006 (22.6\%) and 2008 (22.8\%), although significantly lower VMC was reported in 2007 (15.7\%), which most likely was the result of the beginning of a drought that persisted for the rest of the growing season (Fig. 7). In 2007, a significant difference in VMC occurred between the blocks $(P=0.0002)$, ranging from $11.8 \%$ to $16.2 \%$, and between the treatments $(P=$ 0.0402$, LSD $=1.8 \%)$. The highest VMC 2 weeks after rolling was reported for the smooth roller with glyphosate treatment $(16.3 \%)$ and was significantly higher compared with all other treatments (from $12.6 \%$ to $14.0 \%$ ). Differences in VMC 3 weeks after rolling were detected between treatments $(P=0.0107$, LSD $=1.7 \%$ ). The highest VMC 3 weeks after rolling was reported for the smooth roller with glyphosate treatment $(18.4 \%)$, indicating that the accelerated rye termination resulting from herbicide use decreased water uptake by the cover crop. The range of VMC for rolled treatments without glyphosate application was between $14.1 \%$ for the two-stage roller to $16.0 \%$ for the straight bar roller, both at 3.2 $\mathrm{km} \cdot \mathrm{h}^{-1}$. Except for the two-stage roller at 3.2 $\mathrm{km} \cdot \mathrm{h}^{-1}$, no significant differences were found between the rolling treatments without glyphosate in 2007. There were no significant differences in VMC between treatments in 2006 or 2008.

Yield of sweet corn. Significant differences between years $(P<0.0001)$ and significant interactions between years and treatments $(P=0.0886)$ were detected with respect to sweet corn yield; thus, data were analyzed separately for each year. The highest sweet corn yield of $15,613 \mathrm{~kg} \cdot \mathrm{ha}^{-1}$ was obtained in 2006 followed by $10,158 \mathrm{~kg} \cdot \mathrm{ha}^{-1}$ in 2008 and the lowest yield of $3,513 \mathrm{~kg} \cdot \mathrm{ha}^{-1}$ was obtained in $2007\left(\mathrm{LSD}=756 \mathrm{~kg} \cdot \mathrm{ha}^{-1}\right)$. No significant differences in yield among the treatments were found in all growing seasons: in $2006(P=0.1567)$, in $2007(P=$ $0.2570)$, and in $2008(P=0.3767)$. The results of sweet corn yield in growing season and each treatment are summarized in Table 4.

Significant yield reduction for sweet corn in 2007 was entirely associated with water deficit as a result of a severe drought in Alabama. Weather data have shown that in 2006, during the period from cover crop termination to the sweet corn harvest, the
Cullman location received $34.5 \mathrm{~cm}$ of rainfall. The rainfall amounts were fairly uniformly distributed during the 2006 growing season (Fig. 6) and helped produce the highest sweet corn yield. In 2007, $19.1 \mathrm{~cm}$ of rainfall was recorded during the same period (Fig. 7), which was only $55 \%$ and $44 \%$ of the rainfall amounts for the same period in 2006 and 2008, respectively, which caused a significant yield reduction as a result of a prolonged soil-water deficit. In 2008, during the period from rye termination to sweet corn harvest, rainfall totaled $43.0 \mathrm{~cm}$ and was the highest of the three growing seasons (Fig. 8). Although there was enough rainfall in 2008 , yield was $\approx 34.9 \%$ lower than in 2006. Yield reduction may have been related to wet periods in May and July during

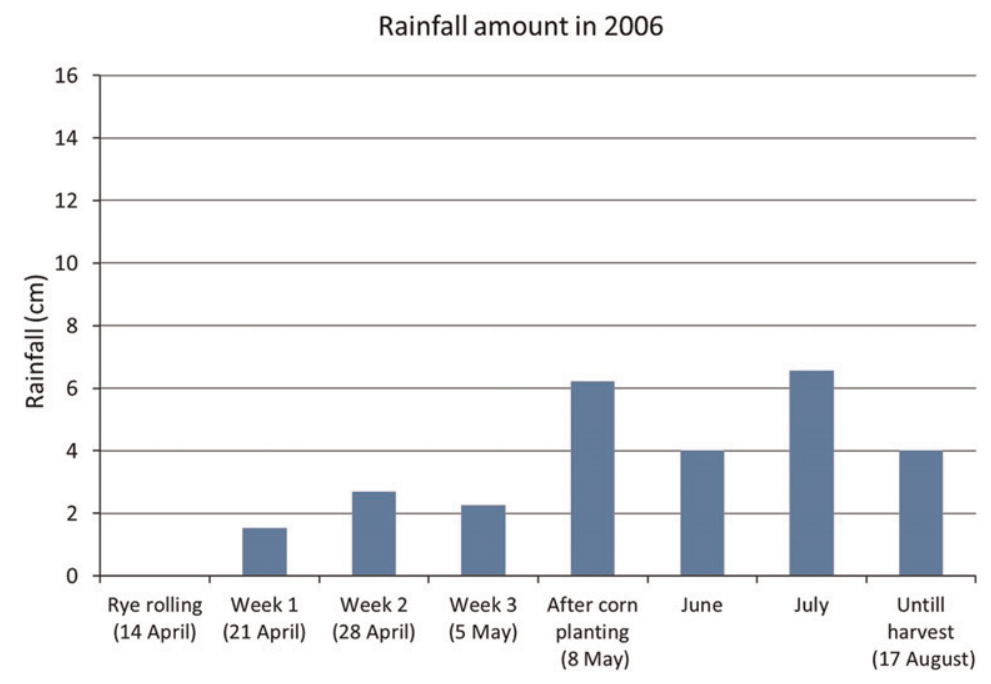

Fig. 6. Seasonal rainfall amounts recorded from the date of rye cover crop termination by rollers/crimpers until sweet corn harvest in 2006.

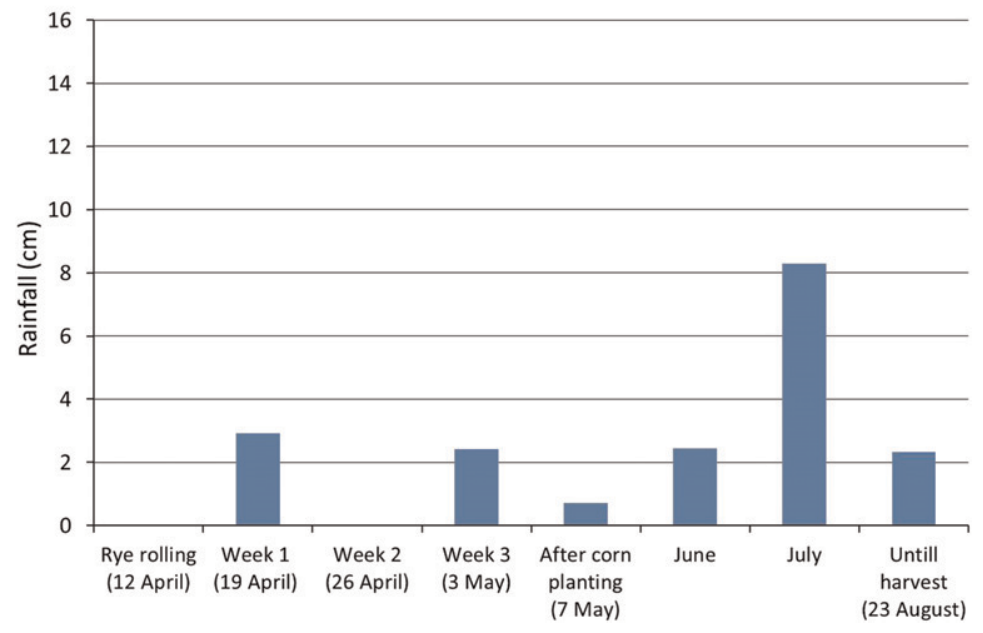

Fig. 7. Seasonal rainfall amounts recorded from the date of rye cover crop termination by rollers/crimpers until sweet corn harvest in 2007.

Table 4. Roller type and speeds effect on sweet corn yield for three growing seasons.

\begin{tabular}{lcccr}
\hline & & 2006 & 2007 & 2008 \\
\cline { 3 - 5 } Roller type & Speed $\left(\mathrm{km} \cdot \mathrm{h}^{-1}\right)$ & \multicolumn{3}{c}{ Sweet corn yield $\left(\mathrm{kg} \cdot \mathrm{ha}^{-1}\right)$} \\
\hline Straight bar & 3.2 & $16,016.1$ & $4,566.5$ & $9,194.2$ \\
& 6.4 & $15,326.5$ & $3,923.7$ & $10,664.8$ \\
Smooth roller with crimping bar & 3.2 & $14,754.8$ & $3,330.8$ & $12,012.8$ \\
& 6.4 & $16,606.0$ & $3,413.2$ & $9,648.7$ \\
Two-stage roller & 3.2 & $16,467.7$ & $3,095.0$ & $10,140.7$ \\
& 6.4 & $17,171.6$ & $2,882.1$ & $9,989.7$ \\
Smooth drum with glyphosate & 6.4 & $12,950.4$ & $3,381.1$ & $9,454.6$ \\
\multicolumn{2}{c}{$P$-value, $\alpha=0.10$ significant level } & $0.1567(\mathrm{Ns})$ & $0.2570(\mathrm{Ns})$ & $0.3767(\mathrm{NS})$ \\
\hline
\end{tabular}

NS $=$ non-significant. 
the 2008 growing season and to the fact that the corn was planted 1 week later compared with 2006 and 2007. Contrary to 2006, rainfall with $11 \mathrm{~cm}$ of rain received from planting (14 May) to the end of May and $15 \mathrm{~cm}$ in July, which might have supplied too much moisture to the soil and negatively affected yield.

Comparing sweet corn yields from particular roller types and operating speeds using the single degree of freedom contrast (Table 5 ), there was no difference in yield between the two speeds averaged overall roller types. Likewise, there was no significant difference in yield (averaged over the two operating speeds) among straight bar roller, smooth roller with crimper, and two-stage roller in the 2006 and 2008 growing seasons. In 2007, significant differences in yield averaged over operating speeds were observed between the straight bar roller and two-stage roller crimper $(P=0.0807)$ and between the straight bar roller and smooth roller with crimping bar in 2008 was not uniformly distributed (Fig. 8)

$(P=0.0158)$. Compared with the smooth drum with glyphosate application in 2006, significantly higher yield was reported for the two-stage roller at $6.4 \mathrm{~km} \cdot \mathrm{h}^{-1}(P=0.0259)$ and for smooth roller crimper at $3.2 \mathrm{~km} \cdot \mathrm{h}^{-1}$ $(P=0.0313)$ and at $6.4 \mathrm{~km} \cdot \mathrm{h}^{-1}(P=0.0118)$. It is not clear why the smooth drum with glyphosate treatment resulted in lower yield compared with mechanical rolling. One might speculate that glyphosate inhibited emergence of corn; however, there are no data suggesting glyphosate's negative effects on emergence. It has been observed by the authors that herbicide application before plastic installation inhibited vegetable growth, especially in dry years. Lower yield resulting from weeds competition must be ruled out because all treatments received the same post-emergence herbicide application to control weeds. Also, faster rye desiccation resulting from glyphosate application could promote faster release of allelopathic chemicals from the rye residue and slow down corn development (Barnes and

\section{Rainfall amount in 2008}

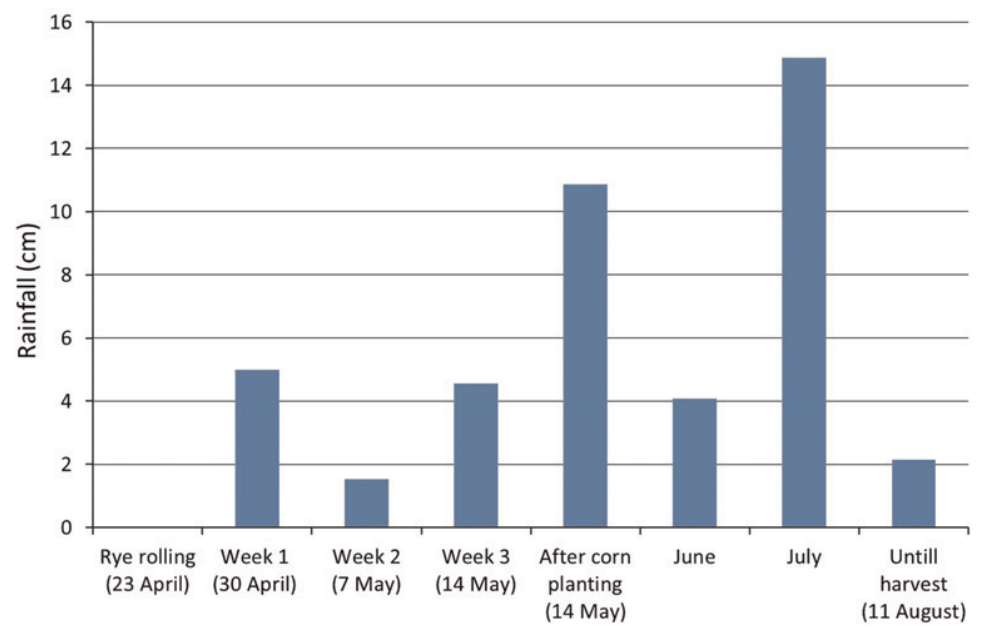

Fig. 8. Seasonal rainfall amounts recorded from the date of rye cover crop termination by rollers/crimpers until sweet corn harvest in 2008.

Table 5. Single degree of freedom contrasts results comparing sweet corn yield between different roller design treatments and operating speeds. ${ }^{z}$

\begin{tabular}{|c|c|c|c|}
\hline \multirow[b]{3}{*}{ Contrast description } & \multicolumn{3}{|c|}{ Year } \\
\hline & 2006 & 2007 & 2008 \\
\hline & \multicolumn{3}{|c|}{$P$} \\
\hline Operating roller speed $3.2 \mathrm{~km} \cdot \mathrm{h}^{-1}$ vs. $6.4 \mathrm{~km} \cdot \mathrm{h}^{-1}$ & 0.4837 & 0.5119 & 0.6365 \\
\hline Straight bar roller vs. two-stage roller & 0.9932 & 0.0807 & 0.3231 \\
\hline Straight bar roller vs. smooth roller crimper & 0.2951 & 0.0158 & 0.8801 \\
\hline Two-stage roller vs. smooth roller crimper & 0.2988 & 0.4270 & 0.3995 \\
\hline $\begin{array}{l}\text { Straight bar roller at } 3.2 \mathrm{~km} \cdot \mathrm{h}^{-1} \text { vs. smooth drum }+ \\
\text { glyphosate }\end{array}$ & 0.0568 & 0.0926 & 0.8379 \\
\hline $\begin{array}{l}\text { Straight bar roller at } 6.4 \mathrm{~km} \cdot \mathrm{h}^{-1} \text { vs. smooth drum }+ \\
\text { glyphosate }\end{array}$ & 0.1320 & 0.4268 & 0.3474 \\
\hline $\begin{array}{l}\text { Two-stage roller at } 3.2 \mathrm{~km} \cdot \mathrm{h}^{-1} \text { vs. smooth drum }+ \\
\text { glyphosate }\end{array}$ & 0.2464 & 0.9407 & 0.0564 \\
\hline $\begin{array}{l}\text { Two-stage roller at } 6.4 \mathrm{~km} \cdot \mathrm{h}^{-1} \text { vs. smooth drum }+ \\
\text { glyphosate }\end{array}$ & 0.0259 & 0.9622 & 0.2214 \\
\hline $\begin{array}{l}\text { Smooth roller crimper at } 3.2 \mathrm{~km} \cdot \mathrm{h}^{-1} \text { vs. smooth drum }+ \\
\text { glyphosate }\end{array}$ & 0.0313 & 0.6731 & 0.8788 \\
\hline $\begin{array}{l}\text { Smooth roller crimper at } 6.4 \mathrm{~km} \cdot \mathrm{h}^{-1} \text { vs. smooth drum }+ \\
\text { glyphosate }\end{array}$ & 0.0118 & 0.4642 & 0.6748 \\
\hline
\end{tabular}

Putman, 1986). In the 2007 growing season, significantly higher sweet corn yield was reported for straight bar roller at $3.2 \mathrm{~km} \cdot \mathrm{h}^{-1}$ compared with the smooth drum with glyphosate $(P=0.0926)$. In 2008 , higher yield was generated only by the two-stage roller at 3.2 $\mathrm{km} \cdot \mathrm{h}^{-1}$ compared with the smooth drum rolling plus chemical application $(P=0.0564)$.

\section{Conclusion}

Three different roller designs operated at $3.2 \mathrm{~km} \cdot \mathrm{h}^{-1}$ and $6.4 \mathrm{~km} \cdot \mathrm{h}^{-1}$ were compared in three growing seasons in northern Alabama to determine the effects of roller type and speed on rye cover termination, soil volumetric moisture content, and sweet corn yield. A smooth drum roller without crimping bars with glyphosate application was used as a control. Based on the results during three growing seasons, 2 weeks after rolling, termination rates generated by rollers alone were $54.6 \%$, $30.0 \%$, and $50.4 \%$ during 2006,2007 , and 2008 , respectively, compared with smooth drum with glyphosate for which termination rates were from $99 \%$ to $100 \%$. Termination rates 3 weeks after rolling in 2006 increased slightly to $66.0 \%$ and to $60.0 \%$ in 2008 . Rye termination rate data for 2007 were not available 3 weeks after rolling as a result of technical problems. Lower rye termination from the mechanical treatments was most likely caused by the application of the treatments too early in the rye growth stage (flowering) rather than at the recommended milk/soft dough growth stage. Termination dates for each growing season were determined by the recommended planting dates for sweet corn in northern Alabama. Overall, roller type and operating speed did not affect soil moisture after the first and second weeks after rolling. Despite lower termination by the rollers alone (without glyphosate application), sweet corn yield was unaffected by roller treatment. Direct treatment comparison using contrasts showed that in 2006, rollers alone at any speed generated higher corn yield $\left(16,057 \mathrm{~kg} \cdot \mathrm{ha}^{-1}\right)$ compared with the smooth drum with glyphosate $\left(12,950 \mathrm{~kg} \cdot \mathrm{ha}^{-1}\right)$ suggesting that applying glyphosate was not beneficial. A similar trend was observed during the droughty growing season of 2007. This finding has a positive implication for organic production systems in which commercial herbicides are not permitted. However, more research is needed to determine the effectiveness of mechanical termination relative to chemical during drought conditions. Results from three growing seasons suggest that ending a rye cover crop at the recommended growth stage of milk/soft dough using rollers/crimpers may delay planting of sweet corn in no-till and possibly affect the yield. Therefore, it is recommended that cover crops be planted as early as possible in the fall (i.e., end of September, beginning of October). The use of rollers/crimpers can still be beneficial in no-till vegetable production in which chemicals may be used or in which the rolling/ crimping operation may be performed at the recommended earliest growth stage for rye. A 
possible solution to speed up the rye desiccation process could be to perform multiple rolling passes over the same cover crop area, but this recommendation should be tested experimentally to determine its effectiveness.

\section{Literature Cited}

Ashford, D.L. and D.W. Reeves. 2003. Use of a mechanical roller crimper as an alternative termination method for cover crop. Amer. J. Altern. Agr. 18:37-45.

Barnes, J.P. and A.L. Putman. 1986. Evidence for allelopathy by residues and aqueous extracts of rye (Secale cereale). Weed Sci. 34:384-390.

Bowen, G., C. Shirley, and C. Cramer. 2000. Managing cover crops profitably. Sustainable Agriculture Network Handbook Series, Book 3, National Agricultural Library, Second Edition, Beltsville, MD.

Brady, N.C. and R.R. Weil. 1999. The nature and properties of soils. 12th Ed. Prentice-Hall, Inc., Upper Saddle River, NJ.

Frans, R., R. Talbert, D. Marx, and H. Crowley. 1986. Experimental design and techniques for measuring and analyzing plant response to weed control practices, p. 37-38. In: Camper, N.D. (ed.). Research methods in weed science. 3rd Ed. Southern Weed Sci. Soc., Champaign, IL.
Gomez, K.A. and A.A. Gomez. 1984. Statistical procedures for agricultural research. 2nd Ed. John Wiley \& Sons, Inc., New York, NY.

Hargrove, W.L. and W.W. Frye. 1987. The need for legume cover crops in conservation tillage production, p. 1-5. In: Power, J.F. (ed.). The role of legumes in conservation tillage systems. Soil Conserv. Soc. of Am., Ankeny, IA.

Hoffman, L.M., L.A. Weston, J.C. Snyder, and E.E. Reginer. 1996. Allelopathic influence of germinating seeds and seedlings of cover crops and weed species. Weed Sci. 44:579-584.

Kern, J.S. and M.G. Johnson. 1993. Conservation tillage impacts on national soils and atmospheric carbon levels. Soil Sci. Soc. Amer. J. 57:200-210.

Kornecki, T.S. 2011. Multistage crop roller. Patent No.: US 7,987,917 B1. Patented 2 Aug. 2011.

Kornecki, T.S., A.J. Price, and R.L. Raper. 2006. Performance of different roller designs in terminating rye cover crop and reducing vibration. Appl. Eng. Agr. 22:633-641.

Kornecki, T.S. and R.L. Raper. 2009. Roller system for cover crop termination. Patent No.: US 7,562,517B1. Patented 20 Oct. 2009.

McGregor, K.C. and C.K. Mutchler. 1992. Soil loss from conservation tillage for sorghum. Trans. ASAE 35:1841-1845.
Nelson, J.E., K.D. Kephart, A. Bauer, and J.F. Connor. 1995. Growth stage of wheat, barley, and wild oat. University of Missouri Extension Service. p. 1-20.

Price, A.J., F.J. Arriaga, R.L. Raper, K.S. Balkcom, T.S. Kornecki, and D.W. Reeves. 2009. Comparison of mechanical and chemical winter cereal cover crop termination systems and cotton yield in conservation agriculture. Journal of Cotton Science. 13:238-245.

Raper, R.L., D.W. Reeves, C.H. Burmester, and E.B. Schwab. 2000a. Tillage depth, tillage timing, and cover crop effects on cotton yield, soil strength, and tillage energy requirements. Appl. Eng. Agr. 16:379-385.

Raper, R.L., D.W. Reeves, E.B. Schwab, and C.H. Burmester. 2000b. Reducing soil compaction of Tennessee Valley soils in conservation tillage systems. J. Cotton Sci. 4:84-90.

Reeves, D.W. 1994. Cover crops and rotations, p. 125-172. In: Hatfield, J.L., and B.A. Stewart (eds.). Advances in soil science: Crops residue management. Lewis Publishers, Boca Raton, FL.

SAS. 2009. Proprietary software release 9.2. SAS Institute Inc., Cary, NC.

Steel, R.G.D. and J.H. Torrie. 1980. Principles and procedures of statistics. A biometrical approach. 2nd Ed. McGraw-Hill Publishing Co., New York, NY. 